Our Nature (2012) 10:71-75

\title{
Field Observations on Stone Curlews in and around Kurukshetra, Haryana, India
}

\author{
R.C. Gupta and T.K. Kaushik* \\ Department of Zoology, Kurukshetra University-136119, Kurukshetra, Haryana, India \\ *E-mail: tarshemkaushik@rediffmail.com
}

\begin{abstract}
Stone Curlew, albeit claimed to be a wader bird of wetlands, is more biased towards dry or semi-dry shores of wetlands and open grasslands in Kurukshetra environs. Although, reported to be a nocturnal bird, it was often observed in day time here. The diurnal visibility of nocturnal Stone Curlews in Kurukshetra certainly points towards its distracted, disturbed, fragmented, scarce habitat so as to compel it to take shelter beside walls in a most unsafe state. The present studies hint towards the fact that, they are summer migratory often seen between April to September but certainly not in November, December and January. They shuttle between different spot in a given area indicating its habitat range up to 1 to $3 \mathrm{~km}$ or so. They are facing difficult circumstances due to loss of habitat; so much so, their feeding spots are not traceable at all. This study proves that the scattered and isolated groups of a nocturnal bird like Stone Curlew are compelled to retire in full view of one and all during daytime and hence are immensely vulnerable. Their survival is threatened. Given the continuance of present adverse conditions, they will no more be seen in the next 10-15 years in Haryana, specially in Kurukshetra.
\end{abstract}

Key words: Stone Curlew, depleted population, Kurukshetra, Haryana.

\section{Introduction}

Stone Curlew is a bird of tropical, subtropical areas with open grassy grounds. It is also known as Dikkops, Thick-Knees, and Thick Knee Bustard (Ali, 1996; Grimmet et al., 1998). Actually it is a medium size wader bird, now often seen only in grass habitats. Its beak has a strong yellow and black color; eyes are yellow and large in size. Its most distinctive feature is its cryptic plumage. Stone curlew birds produces a characteristic wailing sound during night time which resemble the sound of true curlews and hence its name Stone Curlew (Ali, 1996; Grimmet et al., 1998). In so far as its global distribution is concerned, stone curlews are found in Europe, North Africa, and south western Asia including India. Stone curlew is placed in RED-LIST of threatened species of IUCN. This peculiar, uncommon, threatened and extremely mystical bird has not been explored earlier in Haryana and hence the present studies. However, considerable work in field of ornithology has been carried out in Zoology department of Kurukshetra University (Gupta and Kaushik, 2010 a, b, c; Gupta et al., $2010 \mathrm{a}, \mathrm{b}$ ). The present studies have been focused on Eurasian Stone Curlew to generate information on its depleted population status and highly deteriorated 
R.C. Gupta and T.K. Kaushik / Our Nature (2012) 10: 71-75

and fragmented habitat.

\section{Materials and methods}

Kurukshetra is a historical place in India and world. It is located at a distance of 157 $\mathrm{km}$ from New Delhi on NH- I. The geographical position of Kurukshetra district lies between latitude $29^{\circ} 52^{\prime}$ to $30^{\circ} 12^{\prime}$ and longitude $76^{\circ} 26^{\prime}$ to $77^{\circ} 04^{\prime}$. It is basically an agriculture area popular for production of Basmati rice. There are no mountains, no rivers and no natural lakes. However, religious Sarovars are available throughout the districts which are mute witness of the 4000 years old Mahabharata war. The entire area is dotted with small rainy puddles on roadsides in rural and semi-urban surroundings.

Eurasian Stone Curlew was spotted in various places in very isolated small groups in villages like Umri, Ghura, Amin, Dyangla, dugari, Kharkali, Mehra, in Kurukshetra (Fig. 1). Moreover the Stone Curlews were spotted in newly developed cities like Sushant city, Ansal Harmans and sectror- 4 and sector- 8 in Kurukshetra (Fig. $1)$.

The area surveyed is approximately $100 \mathrm{~km}^{2}(10 \times 10)$ spread over Thanesar, Ladwa, Nilokheri and Karnal Tehsil in Kurukshetra and Karnal Districts in Haryana. Visits were made in the morning, forenoon, noon, afternoon and evening and as per convenience, within the constraints of time and other limitations beginning from April 2009-september 2010. Observations of data purely in the form of photographs have been done with the help of Zenith camera with $200 \mathrm{~m}$ tele-lens. Stone Curlew was identified with the help of reference books like Ali (1996) and Grimmet et al. (1998).

\section{Results and discussion}

Popular species of Stone Curlews are Eurasian Stone Curlew (Burhinus oedicnemus), Senegal Thick knee (Burhinus senegalensis), Water Dikkop (Burhinus vermiculatus), Spotted Dikkop (Burhinus capensis), Double-striped thick-knee (Burhinus bistriatus), Peruvian thick Knee (Burhinus superciliaris), Bush Stone Curlew (Burhinus grallarius), Greatthick Knee (Esacus recurvirostris), Breach Stone Curlew (Esacus giganteus).

However, various subspecies of Stone Curlew (Burhinus oedicnemus) are Burhinus oedicnemus distinctus (Bannerman, 1914), Burhinus oedicnemus harterti, Burhinus oedicnemus indicus (salvadori, 1865), Burhinus oedicnemus insularum (Sassi, 1908), Burhinus oedicnemusoedicnemus (Linnaeus, 1758) and Burhinus oedicnemus saharae (Reichnow, 1894).

The present observations hints towards the fact that stone curlew remain in Rest Mood and stationary mode during the day time (Plate 1). Due to total encompassing of land for agriculture, highways, roads, new human inhabitations, there is a scanty proper foraging ground in Haryana for a nocturnal bird like Stone Curlews. There are no previous records available for stone curlews from Haryana.

It is pertinent to mention that Stone Curlew is very sensitive bird. When alarmed, a Stone Curlew usually squats with body pressed to ground and stretches its neck when its coloration affords perfect camouflage (Ali, 1996; Green and Taylor, 1995).

Even a cursorial survey confirms Stone Curlews in Haryana have a distinct Vulnerable Population Status. Our studies 
R.C. Gupta and T.K. Kaushik / Our Nature (2012) 10: 71-75

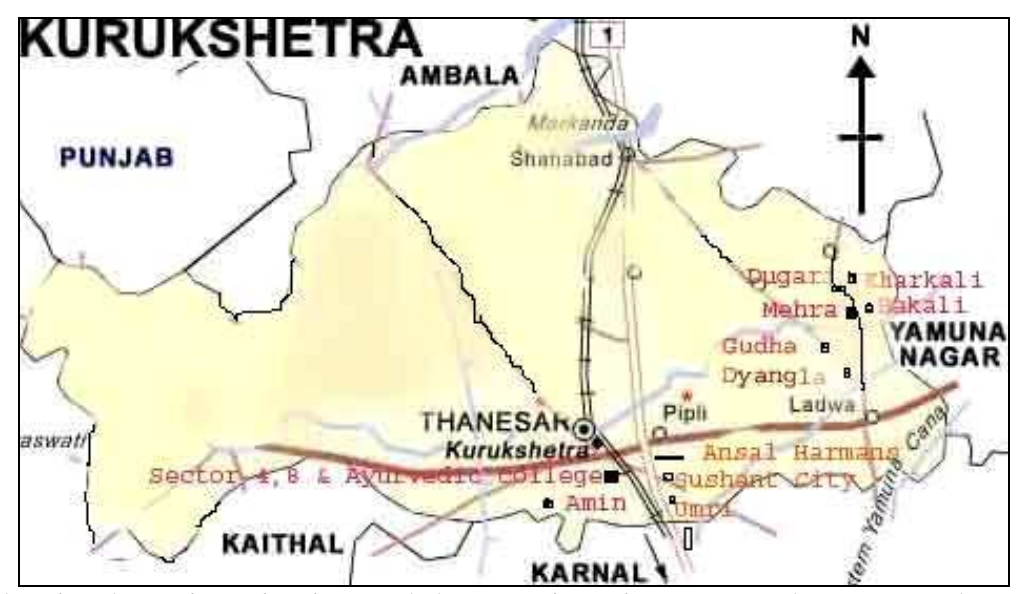

Figure 1. Showing the various sites in Kurukshetra environs in Haryana where scattered groups of Stone Curlews were observed during April, 2009-September, 2011.
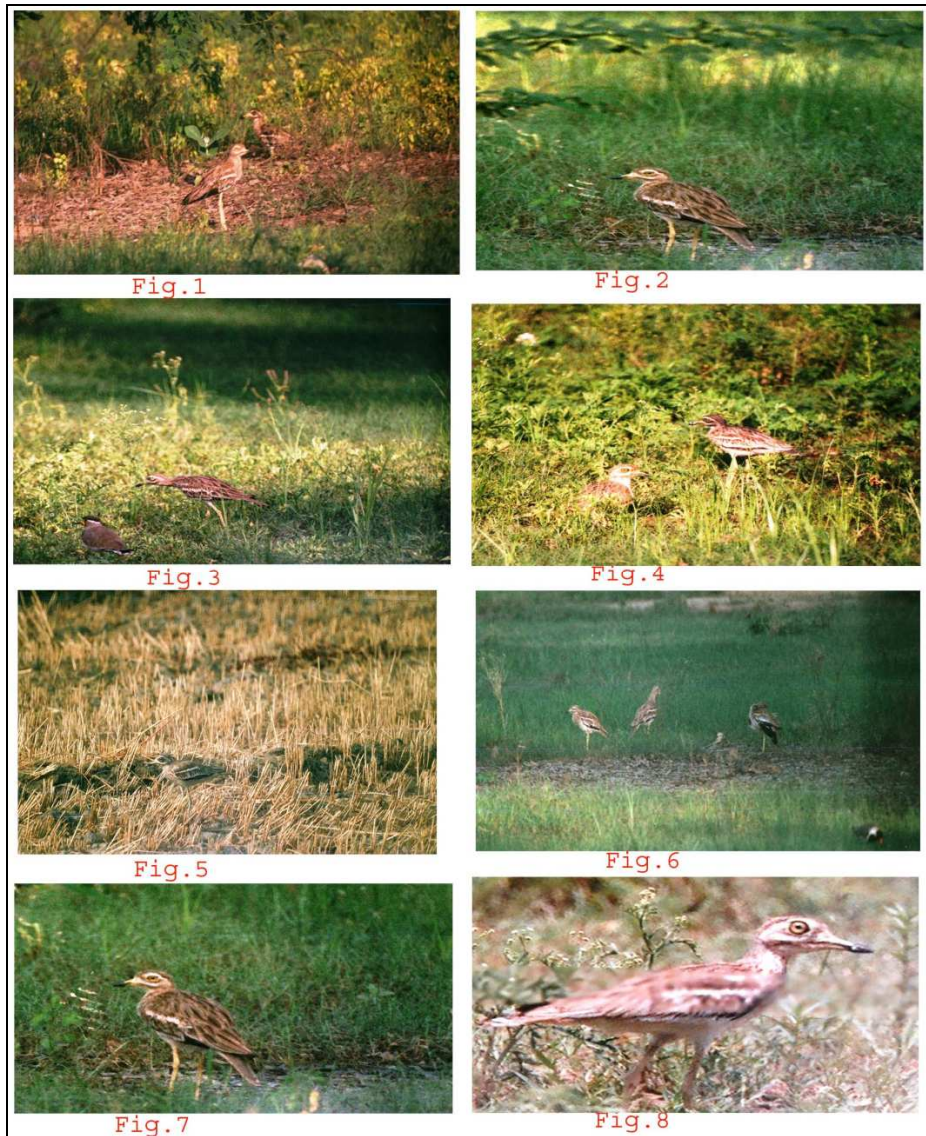

Plate 1. Figures showing Stone Curlews in Kurukshetra (India) environs, observed on grassy ground, in the midst of tall grass and never in water or nearby water. 


\section{R.C. Gupta and T.K. Kaushik / Our Nature (2012) 10: 71-75}

reveal that it's, so called very small groups are available in few hidden spots that too $10-15$ places in a $100 \mathrm{~km}^{2}$ area (Tab. 1). Our observations hint towards the totally obliterated habitat in the last 40 years has $100 \%$ depleted the sensitive roosting sites of a nocturnal bird like Stone Curlew. The direct interference is certainly due to ever expanding agriculture practice and human inhabitations in a fast growing Haryana state. Given, this scenario, sooner than latter, Stone Curlew will be totally wiped out from Haryana (India).

Table 1. Showing the scattered groups of Stone Curlews observed in Kurukshetra district in Haryana (India)

\begin{tabular}{clc}
\hline SN & Locality & $\begin{array}{c}\text { Number of Eurasian } \\
\text { Stone Curlews }\end{array}$ \\
\hline 1 & Sector-4 & $20-25$ \\
\hline 2 & Sector-8 & $25-30$ \\
\hline 3 & Sushant City & $8-10$ \\
\hline 4 & Ansal Harmans & $5-7$ \\
\hline 5 & Umri & $3-4$ \\
\hline 6 & Amin & $7-8$ \\
\hline 7 & Gudha & $3-5$ \\
\hline 8 & Dyangla & $6-8$ \\
\hline 9 & Dagari & 2 \\
\hline 10 & Kharkali & $7-8$ \\
\hline 11 & Mehra & $6-7$ \\
\hline 12 & Bakali & $3-4$ \\
\hline
\end{tabular}

The present studies reveal that within a given area say present site of studies i.e. Ayurvedic College and Sushant city in Kurukshetra, including a cluster of villages mentioned previously, Stone Curlews shuttle between different spot indicating its habitat range upto 1 to $3 \mathrm{kms}$ or so only. Green and Taylor (1995) reported that Stone curlews were nocturnal and travelled up to about $3 \mathrm{~km}$ from their nest to forage. The adjoining accumulated fresh water pool was rich in variety of amphibians (frogs, toads) and small reptiles and rodents. Perhaps these served as its food. The most important and significant findings of the present observations concern two facts viz., (i) the available groups of Stone Curlews are few and far between and do consist of miniscule number of birds and are certainly extremely threatened in Haryana State; (ii) Stone Curlews are facing difficult circumstances due to $100 \%$ loss of habitat, so much so, their feeding spots are not traceable at all. It was observed that during day time, these birds were seen in motionless mode facing disturbances and adverse conditions.

To prevent extinction of stone curlew in Haryana and adjoining areas a technique namely SCARE (Stone Curlew Access Response Evaluator) may be applied to effectively evaluate feature trends and development of habitat creation measures in context of this precious and near extinction of avian peculiarity. Based upon present field observations, it is recommended specially in context of Haryana state, HUDA (Haryana Urban Development authority) must necessarily create "BioDiversity Cradles" or "Bio-Diversity Corners" as isolated pockets of space in the accompaniment of present practice of having "Parks" and "Green Belts". These "Zones" should have a mixture of landscape features having shallow water pools rich in small fish populations, Acacia arabica, treeplantations, grass-ladden mounds and depressions. Stone Curlew being a ground breeder, the above suggested measures would supplement the conservation efforts not only for stone curlew but far other scores of other birds. From the evolutionary point of view, the present observations indicate distinctly the Stone Curlew in Haryana was always found stationed in a wild grass strewn courts of buildings and outstretches of agriculture fields in villages 


\section{R.C. Gupta and T.K. Kaushik / Our Nature (2012) 10: 71-75}

and never in familiar habit of mud flats at the shallow shores of pools, ponds etc. hence, its status as a wader-bird need to be rediscovered and re-determined. In addition, these birds could not be ever traced in winter season of 2010-11. As such, it is argued that just as in Africa and other parts of south western Asia, stone Curlews in Haryana (India) are summer migratory. Reportedly, it winters in Africa. If in European habitats 307-350 pairs were observed in 2005 and hence placed in Red Data Book (1996-2001) and labeled as a species of international concern, the situation of stone curlews in Haryana (India) is worse as per the present observations. Its home range also seems to be fragmented in Kurukshetra as these groups were seen in 23 spots, one few kms away from the other (Tab. 1). Existence of fragmented habitat is the proof, its extremely poor plight in the absence of availability of sufficient continuous patches of grassy open grounds in Kurukshetra. Stone curlew should be given the status of "Bird of Conservation" concern by Govt. of India in due course of time and its conservation programme can be easily conceived and executed due to the isolated pockets of grassy open spaces availability in urban estate precincts across the state. Due efforts have the potentials to impart chances of recovery of lost grounds in case of Stone curlews in Haryana state by first implementing the plan in Kurukshetra by designing few crucial spots as sites of special scientific interests. Also, the conservation of stone Curlews in Haryana can be made a part of Haryana rural development programmes.

Precisely speaking, Stone curlews in Haryana are facing a situation which may culminate in its complete annihilation due to cent-percent habitat loss due to expansion of agriculture practices and ever and very rapid expansion of human habitats in cities, towns and even villages and so called Deras. The situation can be retrieved by executed few meaningful plans targeting avifauna conservation in consonance with habitat improvement.

\section{Acknowledgements}

The authors are thankful to their respective better half for granting allowance of time for field surveys.

\section{References}

Ali, S. 1996. The book of Indian birds. Salim Ali centenary Edition, Revised and Enlarged. Oxford University Press.

Green, R.E. and C.R. Taylor 1995. Changes in Stone Curlew Burhinus oedicnemus distribution and abundance and vegetation height on chalk grassland at porton Down, Wiltshire. Bird Study 42: 177-181.

Grimmet, R., C. Inskipp and T. Inskipp 1998. Birds of the Indian subcontinent. Oxford University Press, Delhi. p. 888.

Gupta, R.C. and T.K. Kaushik 2010a. Determination of the domain of spectrum concerning diversity of endangered winter visitor wetland birds in Haryana. J. Expt. Zool. India 13(2): 349-354.

Gupta, R.C. and T.K. Kaushik 2010b. Computation of wetland birds in rural areas of Kurukshetra, Haryana, India. J. Natcon. 22(1): 1-11.

Gupta, R.C. and T.K. Kaushik 2010c. Understanding rural ponds' migratory avian diversity in Panchkula district in Haryana, India. J. $A d v$. Zool. India 31(2): 117-123.

Gupta, R.C., S. Kumar and T.K. Kaushik 2010a. Computation of route specific Avi-faunal diversity in Morni hills in Panchkula district in Haryana state in India. J. Adv. Zool. India 31(1): 1-9.

Gupta, R.C., T.K. Kaushik and S. Kumar 2010b. An account concerning arrival and departure time of few selected winter migratory birds in Haryana rural ponds. Environ. Cons. J. 11(1-2): 1-9. 